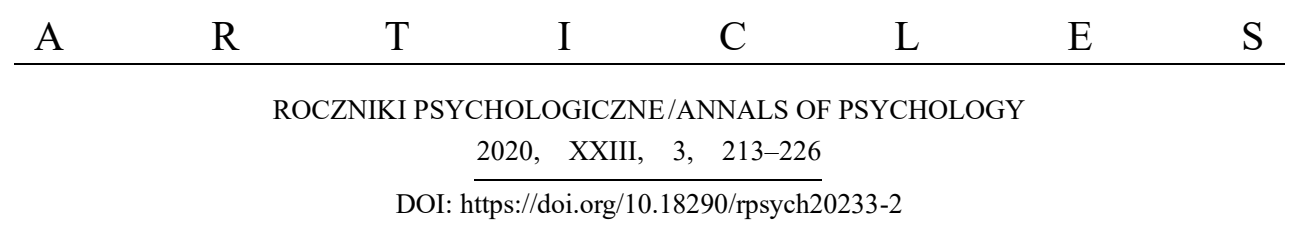

GARY P. LATHAM

Rotman School of Management

University of Toronto

\title{
THE CREDIBILITY OF GOAL PRIMING RESEARCH IN WORK AND ORGANIZATIONAL PSYCHOLOGY
}

Four criteria attest to the credibility of subconscious goal effects on organizational related behavior. First, the findings support hypotheses derived from goal setting theory. Second, the empirical experiments, conducted in both laboratory and field settings, have both internal and external/ecological validity. The dependent variables include brainstorming, negotiations, task/job performance, and satisfaction with customer service. Third, the results of these experiments have been shown to be robust with regard to exact and conceptual replications. Fourth, a meta-analysis has shown the practical as well as the theoretical significance of these findings. A goal primed in the subconscious and a consciously set goal have additive effects on job performance and negotiations.

Keywords: goal setting theory; primed/subconscious goals; exact and conceptual replications; organizational behavior.

Correspondence concerning this article can be sent to GARY P. LATHAM, PhD, Rotman School of Management, University of Toronto, 105 St. George Street, Toronto, Ontario, Canada M5S 3E6; e-mail: latham@rotman.utoronto.ca; ORCID: https://orcid.org/0000-0001-5922-0321.

This paper is based in part on a keynote address to the Congress of the Polish Association of Organizational Psychology, Lublin, Poland in 2018. The author thanks John Bargh, Janel Gauthier, Milton Hakel, Guy Itzchakov, Barbara Kożusznik, and Edwin Locke for their constructive comments on an earlier copy of this paper. 
The results of goal priming research in social psychology have endured a replication crisis (Kahneman, 2012). The crisis occurred as a result of the failure of several highly cited experiments to be replicated by others (e.g., Shanks et al., 2013). The crisis arguably ended when Weingarten et al. (2016) published the findings of a meta-analysis on social psychology experiments. The analysis revealed a moderate behavioral effect of priming words connected to goal representations of behavioral outcomes (e.g., time spent on a task). However, the meta-analysis did not include experiments on organizational related behavior. Hence, the purpose of this article is to examine the credibility of goal priming research in work and organizational psychology (W-O) through an enumerative review of the literature.

Four criteria support the credibility of W-O goal priming-performance effects. First, unlike the largely atheoretical findings in social psychology experiments in this domain, the results obtained in W-O psychology are consistent with the hypotheses derived from theory, specifically, goal setting theory (GST). Thus the concerns of skeptics that the results of goal priming experiments might be due to "harking" (i.e., hypothesizing after the results are known) should be minimal.

Second, in addition to internal and external validity, the results of the priming experiments in W-O psychology have ecological validity. The results of field experiments, where employees were randomly assigned to conditions, are consistent with those obtained in laboratory settings. Evidence of external validity has been shown through the use of different dependent variables (e.g., brainstorming, job performance, customer service ratings) and participants from different populations (e.g., college students, employees, and customers).

Third, the results of priming experiments in W-O psychology have withstood both exact and conceptual replications. The benefit of exact replications is that they reveal whether findings from the original experiment are robust. Furthermore, an exact replication makes it possible to correct Type I errors in earlier experiments (Molden, 2014). The benefit of a conceptual replication is that with every difference that is introduced (e.g., independent and dependent variables) the confirmatory power of the replication increases (Locke, 2015).

Finally, a meta-analysis of $\mathrm{W}-\mathrm{O}$ priming experiments shows the theoretical and practical significance of goals primed in the subconscious (Chen et al., 2020).

Before describing experiments that illustrate each of these four criteria, goal setting theory (Locke \& Latham, 1990, 2002, 2013) is briefly described, as is the automaticity model of primed goals (Bargh, 1990, 2017). 


\section{GOAL SETTING THEORY}

To qualify as a theory, causal relationships must be specified, moderators or boundary conditions of these causal relationships must also be specified, and the mediators that explain the causal relationships must be identified (Latham, 2012). GST first and foremost states that consciously set goals that are specific and challenging lead to (i.e., cause) higher performance than setting vague or abstract goals (e.g., do my best, become a kinder person) or having no goals at all. Moreover, given the presence of four moderators, the higher the specific goal, the higher an individual's performance.

The four moderators in GST are ability, goal commitment, performance feedback, and situational constraints/resources. If ability and/or resources are lacking, supervisors may abuse their subordinates (Mawritz et al., 2014). Feedback is critical for determining what people should continue doing, stop doing, or start doing to attain their goal. If commitment to attain a goal is lacking, by definition no goal exists for that individual.

The mediators that explain the goal-performance effect are choice, effort, persistence, and strategy. That is, people can choose to set a specific goal, a vague goal, or no goal and simply meander. They can choose to set a difficult, moderately difficult, or an easy goal to attain. Similarly, they can exert a great deal of effort, moderate effort, or little or no effort in their pursuit of a goal. People who set and are committed to attaining a specific, high goal typically persist until the goal is reached.

When pursuing a performance/outcome goal, people draw upon their extant strategies. However, when those strategies are not adequate for goal attainment, a learning rather than a performance goal should be set. A learning goal shifts attention from a specific desired outcome to that of discovering/developing new strategies for task mastery (Winters \& Latham, 1996; Seijts \& Latham, 2005).

There are four types of consciously set goals: (1) vague, attitudinal versus specific, (2) performance, (3) learning, and (4) behavioral goals. The question addressed in W-O priming experiments is whether GST also applies to subconscious goal-performance effects. The automaticity model (Bargh, 1990, 2017) implies that the answer is yes. 


\section{THE AUTOMATICITY MODEL}

Bargh's (1990) automaticity model asserts that a prime is an external stimulus in the environment that activates a mental representation of a goal that has been stored in memory. This mental representation of a goal, once activated by features of a situation, guides behavior in the absence of conscious deliberation or awareness. Moreover, a goal primed in the subconscious shows the same qualities as do goals that are set consciously (Bargh et al., 2001). The only major difference between a conscious and a subconscious goal is that the latter activates goal pursuit in the absence of awareness of the primed goal's guiding influence (Bargh, 2005).

Primes can be subliminal where the stimulus in the environment is presented below focal awareness. Primes can also activate a mental representation of a goal supraliminally. That is, the individual is aware of the prime but unaware of its influence on his or her behavior. Bargh (1992) has argued for the use of supraliminal priming because of its ecological validity relative to subliminal priming techniques.

\section{CAUSAL GOAL PRIMING-PERFORMANCE EFFECTS}

Consistent with GST and empirical research on consciously set goals, goal priming-performance effects have been consistently found. For example, Stajkovic et al. (2006) primed a goal for achievement by requiring students to make sentences from scrambled words which included 12 achievement related words (e.g., win, strike, compete). Participants who had been randomly assigned to the experimental condition brainstormed more uses for a coat hanger than those in the control condition. Moreover, the causal effect of the subconscious goal for achievement was additive with a consciously set specific, high goal. This suggests that the two main effects act in parallel. ${ }^{1}$

A conceptual replication was conducted by Shantz and Latham (2009) in a call center. Again, in addition to a main effect for the consciously set goal for the amount of money to be raised from donors, there was a main effect for the

\footnotetext{
${ }^{1}$ Yet there is currently no evidence that conscious goals operate through different mental processes than goals primed in the subconscious. Imaging as well as behavioral priming experiments show a high degree of similarity in processing signatures between pursuits of conscious versus subconscious goals, that is, same brain regions and same subprocesses (Pessiglione et al., 2007; Takarada \& Nozaki, 2018).
} 
subconscious goal. The prime was a backdrop of a photograph of an individual winning a race shown underneath the typed script written by management for employees to use in telephone conversations with potential donors. No photograph was presented in the control condition. Two exact replications provided support for the subconscious goal-performance effect in terms of dollars raised from donors (Shantz \& Latham, 2011).

Stajkovic et al. (2018) examined causality by inserting achievement-related words in a Monday morning email that a CEO sends weekly to employees. Unlike social psychology experiments where the time lag between the manipulation of the independent variable and the dependent variable is typically no longer than a few minutes, the time lag in this work setting was a 5-day work week. Employees randomly assigned to the experimental condition performed significantly better than the employees in the control condition.

GST emphasizes the necessity for making a consciously set goal specific. Hence, Latham and Piccolo (2012) tested the importance of this assertion for priming a subconscious goal. In the context specific goal condition, employees in a call center were shown a photograph of employees making phone calls; in the general goal condition, the employees were shown the photograph of an individual winning a race. Consistent with GST, employees who were exposed to the context specific prime raised $85 \%$ more money than the employees in the control condition and $16 \%$ more money than the employees who had been exposed to the photograph of the racer over a 4-day work week.

Noteworthy is that the dependent variable in the field experiments conducted by Shantz and Latham (2009, 2011), Latham and Piccolo (2012), and Stajkovic et al. (2018) was assessed by the respective organization's computers. Furthermore, there was no experimenter-employee contact in the Latham and Piccolo (2012) and Stajkovic et al. (2018) experiments. Hence, rival hypotheses that causality was due to experimenter bias and/or demand effects can be rejected.

To eliminate the rival hypothesis that almost any photograph has a beneficial effect on performance, Itzchakov and Latham (2020) conducted two laboratory experiments where the findings were replicated. The results also generalized to a work setting. Employees who were primed with the photograph of the racer obtained higher customer service ratings than those who had been randomly assigned to the control condition where a photograph of a tree was shown.

Causal priming effects in W-O psychology obtained in field experiements have not been limited to showing increases in job performance. Three experiments, of which one was a conceptual replication and the other an exact replica- 
tion revealed that a yellow sticker of a happy face on a sales receipt increased satisfaction with the customer service an individual received in a retail store relative to the control conditions (Brcic \& Latham, 2016).

\section{LEARNING GOALS}

As noted earlier, GST differentiates performance, learning, and behavioral goals. In the preceding experiments, performance goals were primed. Chen and Latham (2014) investigated the effect of priming a learning goal, a performance goal, and both a learning and a performance goal together on a task that requires the acquisition of knowledge to perform it rather than sheer effort and persistence. Consistent with the results obtained with consciously set goals in an earlier laboratory experiment (Winters \& Latham, 1996), a main effect was only obtained in the primed learning goal condition, namely, where participants saw a photograph of Rodin's "Thinker." Neither the performance goal nor the combination of the performance goal and the learning goal increased performance.

\section{BEHAVIORAL GOALS}

The positive effect of goal priming has been shown on tasks that are dynamic and interactive in nature. Ganegoda et al. (2016) obtained main effects for both a consciously set behavioral goal and a primed goal for fairness on a negotiation task. The primed goal was manipulated through the use of a 10x10 matrix of letters in which fairness related words, which participants in the experimental condition were instructed to discover, were embedded. Both the primed and the behavioral goal counteracted the self-serving tendency to attain a consciously set specific, high performance goal.

As is the case for consciously set goals (Latham \& Locke, 1975; Locke \& Latham, 1990), goals can be primed in the subconscious to increase the performance of a team (Latham et al., 2020). Of the three priming experiments, one was a conceptual replication and the other was an exact replication. The behavioral goal for a team's members in the experimental condition to cooperate with one another was primed by a context specific photograph of people working together. A main effect on team performance was obtained in each of the three experiments. 


\title{
GST MODERATORS
}

\begin{abstract}
Ability
That ability moderates the primed goal-performance effect can be inferred from the Chen and Latham (2014) experiment on cognitive ability, that is the acquisition of task knowledge. On a task that was too complex for participants to perform on the basis of sheer effort and persistence, neither a consciously set performance goal (Winters \& Latham, 1996) nor a primed performance goal increased performance. Only a learning goal that was primed, as was the case for a learning goal that had been set consciously (Winters \& Latham, 1996) improved performance relative to the control condition.
\end{abstract}

\section{Goal Commitment}

In the second and third experiments on team performance (Latham et al., 2020), goal commitment was shown to moderate the primed goal-task performance effect. The task in both experiments involved a social dilemma where people were tempted by a self-set goal to behave in a pro-self manner rather than a pro-social manner. In both experiments, where play versus actual money was given to the participants, two behavioral measures (Experiment 2) and a self-report (Experiment 3) indicated goal commitment was higher in the experimental than in the control condition.

\section{Performance Feedback}

Consistent with GST, Itzchakov and Latham (2020) found no main effect for feedback by itself on two measures of task performance. Consistent with GST, feedback moderated the "downstream effect" of a self-set goal that was the result of a primed goal. As noted earlier, the conscious goal was self-set without any prompting by an experimenter.

\section{Situational Resources/Constraints}

Axiomatic in the automaticity model is that it is features of a situation that cue or activate a goal, in the absence of awareness, that has been stored in memory. 


\section{Individual Differences}

In addition to the moderators specified by GST, both conscientiousness and core self-evaluation have been shown to moderate conscious goal performance effects (Barrick et al., 1993; Bipp et al., 2015, respectively). Similarly, a laboratory experiment revealed that those individuals who had been primed with a difficult performance goal subsequently chose a significantly higher conscious goal than those who had been primed with an easier goal. Conscientiousness moderated this primed goal-performance effect (Latham et al., 2017).

Two laboratory and one field experiment found support for the hypothesis that CSE moderates the relationship between a primed goal for achievement and task/job performance. In short, it appears that a primed achievement goal does not increase performance for individuals with low CSE; it increases performance for those who score high on CSE (Itzchakov \& Latham, 2020). These two sets of experiments (Itzchakov \& Latham, 2020; Latham et al., 2020) show that personality plays a role in the effect of priming goal pursuit.

\section{MEDIATORS}

\section{Effort}

As noted earlier, effort is a mediator in GST. The theory states that there is a linear relationship between goal difficulty level and task/job performance (Locke \& Latham, 1990). Latham et al. (2017) tested this assertion for a goal primed in the subconscious. Participants were shown one of three photographs, namely a weight lifter exerting effort to raise 20,200 , or 400 pounds. They were then asked to "press as hard as you can" on a digital weight scale. There was a significant linear relationship between the difficulty level connoted by each of the three primes and subsequent performance. In short, effort can be primed, and an increase in effort leads to an increase in performance.

\section{Choice}

Choice is integral and indispensable in a motivational analysis of behavior because choices account for the decision to set a goal, its difficulty level, and the effort expended to attain it. Again, using photographs of weight lifters, Latham et al. (2017) found that a difficult goal primed in the subconscious led to the 
subsequent choice of a higher self-set goal than one that was chosen when an easier goal had been primed.

\section{Persistence}

Recalling past instances of achievement striving increased the time spent on an anagram task (DeMarree et al., 2012).

\section{Strategy}

Developing a plan/strategy is inherent in the setting of a learning goal. A photograph of Rodin's "Thinker" was used successfully by Chen and Latham (2014) to prime a learning goal. As noted above, only this learning goal increased performance on a task that was complex for people.

\section{Consciously Set Goals}

In a laboratory experiment, Stajkovic et al. (2016, Experiment 1) primed self-efficacy. The prime was supraliminally induced by requiring participants to make sentences out of scrambled words before brainstorming uses for a coat hanger. Conscious self-efficacy mediated the primed efficacy-task performance relationships.

In the Stajkovic et al. (2018, Experiment 2) field experiment where achievement related words had been embedded in the email sent to employees, a measure of conscious motivation mediated the primed goal-task performance effect.

Latham et al. (2017), in a laboratory experiment, found that a primed goal increased the difficulty level of a self-set goal. The self-set goal was prompted by the request of an experimenter. This self-set goal mediated the primed goal-task performance relationships.

In a follow-up experiment, Itzchakov and Latham (2020) found support for their model in three laboratory experiments and one field experiment. All three showed that the primed goal-task/performance effect is mediated by a self-set goal for a creative task and/or job performance. Unlike the above experiment (Latham et al., 2017), the primed goal led individuals to self-set a goal without a request or prompt by an experimenter to do so.

These findings regarding the mediating role of conscious processes on primed goal effects support the argument put forth by William James (1890) two centuries ago, namely, that an individual's behavior often springs from the sub- 
conscious. Conscious goal setting can be influenced by subconscious processes. However, there is no evidence to date that an implicit motive such as need for achievement mediates the primed goal-performance relationship (e.g., Shantz \& Latham, 2009).

\section{META-ANALYSIS}

The advantage of an enumerative review of the goal priming literature is that it reveals the effectiveness of priming goals in different ways (e.g., the use of words versus photographs), on different types of tasks, in laboratory versus field settings involving participants from different populations. An advantage of a meta-analysis is that quantitative data from the different experiments can be aggregated leading to a more robust point estimate, or a weighted effect size, than is possible from any single goal priming experiment. Thus to complement the preceding enumerative review, a meta-analysis of $23 \mathrm{~W}-\mathrm{O}$ goal priming experiments $(\mathrm{n}=4,543, \mathrm{k}=61)$ was conducted by Chen et al. (2020). The analysis revealed that priming an achievement goal, relative to a control condition, significantly improved task performance in the laboratory, and job performance in work settings as well as the individual's need for achievement $(d=0.62)$. Four moderators of the primed goal task/performance effect were identified. Significantly stronger effects were obtained with a context-specific prime, visual (i.e., a photograph) stimuli as opposed to words, longer time lags, and field rather than laboratory settings.

In all of the above experiments, manipulation checks were conducted to ensure that participants included in the statistical analyses of the data were unaware of the primed goal-performance effect.

\section{CONCLUSION}

Taken together, the results of the enumerative review and the meta-analysis suggest the following conclusions:

1) The automaticity model's (Bargh, 1990; 2005; 2017; Bargh et al., 2010) assertion that goals that are primed and goals that are consciously set have a similar, if not the same, effect on behavior appears to be correct. As the model states, the major difference between the two types of goals is an individual's unawareness-awareness of goal pursuit. 
2) Thus, based on the above assertion, as well as the evidence examined in the enumerative review and by meta-analysis, goal setting theory (Latham \& Locke, 2018; Locke \& Latham, 1990, 2002, 2013) provides a framework for examining primed goal organizational behavior effects. There are no empirically derived findings in the $\mathrm{W}-\mathrm{O}$ literature on goal priming that are inconsistent with GST. Thus, the criticism by Locke (2015) and others (e.g., Cesario, 2014) that the automaticity model lacks a theoretical framework is no longer valid.

3) Locke and Latham's (2004) criticism of GST for failing to take into account subconscious processes has also been eliminated by the above two conclusions. The automaticity model is being integrated with GST (Latham et al., 2017).

4) In support of the above three conclusions, at least 16 experiments in the $\mathrm{W}-\mathrm{O}$ literature have obtained a causal effect for the subconscious goal-performance effect in both laboratory and field settings involving myriad tasks.

5) The primed goal-performance effect is by no means fragile. The metaanalysis revealed stronger effects in field as opposed to laboratory settings.

6) Of practical as well as theoretical significance is the finding of additive task/performance effects, in laboratory and field experiments, for goals primed and goals consciously set. Consistent with GST, this finding is also consistent with findings from experiments on performance, learning, and behavioral goals that were consciously set.

7) Again, in terms of practical significance, both goals, conscious and subconscious, should be set in work settings. Where the task is perceived by employees as complex, it would appear that learning rather than performance goals should be set consciously and subconsciously as the findings from both domains are consistent.

8) Moderators specified by GST that affect the strength of conscious goal performance effects also moderate primed goal performance effects (e.g., ability, performance feedback, goal commitment, situation).

9) The same is true for mediators specified by GST (e.g., choice, effort, persistence, strategy/plan).

10) There is currently no evidence that an implicit motive, such as the need for achievement mediates the primed-goal performance relationships. Instead, the evidence suggests that it is conscious processes such as a self-set goal that mediates primed goal-task/performance effects. Yet this is not the case in many social psychology priming experiments. Thus it remains for future research to identify the context where this is/is not the case. 


\section{FUTURE RESEARCH}

The vast majority of experiments on effects of primed goals on organizational behavior have been limited to dependent variables having to do with task (laboratory) and job performance. In terms of practical significance, these dependent variables need to be expanded to accident prevention in the work place (i.e., safe behavior) and job satisfaction/work engagement. In doing so, the priming technique should be supraliminal, not subliminal. Subliminal priming in the field of advertising has been banned legally in Australia and Great Britian. Unlike subliminal primes, supraliminal primes are fully visible to employees. They are readily perceived; they are overt, not covert. The automaticity model states, and empirical research shows, that in both instances, priming can only activate a goal that already exists in memory. Priming cannot cue people to do something they do not ordinarily consider desirable.

\section{REFERENCES}

Bargh, J. A. (1990). Goal intention: Goal directed thought and behavior are often unintentional. Psychology Inquiry, 1, 248-251

Bargh, J. A. (1992). Why subliminality does not matter to social psychology: Awareness of the subliminal versus awareness of its influence. In R. F. Bornstein \& T. S. Pittman (Eds.), Perception without awareness (pp. 236-255). Guilford Press.

Bargh, J. A. (2005). Bypassing the will: Toward demystifying the nonconscious control of social behavior. The New Unconscious, 12, 37-58.

Bargh, J. (2017). Before you know it: The unconscious reasons we do what we do. Simon and Schuster.

Bargh, J. A., \& Chartrand, T. L. (2000). Studying the mind in the middle: A practical guide to priming and automaticity research. In H. T. Reis \& C. M. Judd (Eds.), Handbook of research methods in social and personality psychology. Cambridge University Press.

Bargh, J. A., Gollwitzer, P. M., Lee-Chai, A., Barndollar, K., \& Trötschel, R. (2001). The automated will: Nonconscious activation and pursuit of behavioral goals. Journal of Personality and Social Psychology, 81, 1014-1027.

Bargh, J. A., Gollwitzer, P. M., \& Oettingen, G. (2010). Motivation. In S. T. Fiske, D. T. Gilbert, \& G. Lindzey (Eds.), Handbook of social psychology. Wiley.

Barrick, M. R., Mount, M. K., \& Strauss, J. P. (1993). Conscientiousness and performance of sales representatives: Test of the mediating effects of goal setting. Journal of Applied Psychology, 78, 715-722.

Bipp, T., Kleingeld, A., Van Den Tooren, M., \& Schinkel, S. (2015). The effect of self-set grade goals and core self-evaluations on academic performance: A diary study. Psychological Reports, 117(3), 917-930.

Brcic, J., \& Latham, G. P. (2016). The effect of priming affect on customer service satisfaction. Academy of Management Discoveries, 2(4), 392-403. 
Cesario, J. (2014). Priming, replication, and the hardest science. Perspectives on Psychological Science, 9, 40-48.

Chen, X., \& Latham, G. P. (2014). The effect of priming learning vs. performance goals on a complex task. Organizational Behavior and Human Decision Processes, 125, 88-97.

Chen, X., Latham, G. P., Piccolo, R. F., \& Itzchakov, G. (2020). An enumerative review and a meta-analysis of primed goal effects on organizational behavior. Applied Psychology. An International Review. https://doi.org/10.1111/apps.12239

DeMarree, K. G., Loersch, C., Briñol, P., Petty, R. E., Payne, B. K., \& Rucker, D. D. (2012). From primed construct to motivated behavior: Validation processes in goal pursuit. Personality and Social Psychology Bulletin, 38, 1659-1670.

Ganegoda, D. B., Latham, G. P, \& Folger, R. (2016). The effect of a consciously set and a primed goal on fair behavior. Human Resouce Management, 55, 789-807.

Itzchakov, G., \& Latham, G. P. (2020). The moderating effect of performance feedback and the mediating effect of self-set goals on the primed goal-performance relationship. Applied Psychology: An International Review, 69(2), 379-414. https://doi.org/10.1111/apps.12176

James, W. (1890). The principles of psychology. Henry Holt and Co.

Kahneman, D. (2012, September 26). A proposal to deal with questions about priming effects (email). Nature, https://www.nature.com/news/polopoly_fs/7.6716.1349271308!/suppinfo File/Kahneman\%20Letter.pdf

Latham, G. P. (2012). Work motivation: History, theory, research, and practice. Sage.

Latham, G. P. (2018). The effect of priming goals on organizational-related behavior. My transition from a skeptic to a believer. In Oettingen, G., Sevincer, T. A., \& Wollwitzer, M. (Eds.), The psychology of thinking about the future (pp. 392-404). Guilford Press.

Latham, G. P., \& Locke, E. A. (1975). Increasing productivity with decreasing time limits: A field replication of Parkinson's law. Journal of Applied Psychology, 60, 524-526.

Latham, G. P., \& Locke, E. A. (2018). Goal setting theory: Controversies and resolutions. In D. Ones, N. Anderson, C. Viswesvaran, \& H. Sinangil (Eds.), Handbook of Industrial, Work \& Organizational Psychology (Vol. 1, pp. 103-124). Sage.

Latham, G. P., \& Piccolo, R. F. (2012). The effect of context specific versus non-specfic subconscious goals on employee performance. Human Resource Management, 51, 535-538.

Latham, G. P. \& Seijts, G. H. (2016). Similarities and differences among performance, behavioral, and learning goals. Journal of Leadership and Organizational Studies, 1-9. (A Distinguished Scholar Invited Essay.)

Latham, G. P., Brcic, J., \& Steinhauer, A. (2017). Toward an integration of goal setting theory and the automaticity model. Applied Psychology: An International Review, 66, 25-48.

Latham, G. P., Hu, J., \& Brcic, J. (2020). The effect of a context-specific primed goal on goal commitment and team performance. Applied Psychology: An International Review, 69(3), 805-833. https://doi.org/10.1111/apps.12207

Locke, E. A. (2015). Theory building, replication, and behavioral priming: Where do we need to go from here? Perspectives on Psychological Science, 10, 408-414.

Locke, E. A., \& Latham, G. P. (1990). A theory of goal setting and task performance. Prentice Hall.

Locke, E. A., \& Latham, G. P. (2002). Building a practically useful theory of goal setting and task motivation: A 35-year odyssey. American Psychologist, 57, 705-717. 
Locke, E. A., \& Latham, G. P. (2004). What should we do about motivation theory? Six recommendations for the twenty-first century. Academy of Management Review, 29, 388-403.

Locke, E. A., \& Latham, G. P. (Eds.). (2013). New developments in goal setting and task performance. Routledge.

Mawritz, M., Folger, R., \& Latham, G. P. (2014). Supervisors' exceedingly difficult goals and abusive supervision: The mediating effects of hindrance stress, anger, and anxiety. Journal of Organizational Behavior, 35, 358-372.

Molden, D. C. (2014). Understanding priming effects in social psychology: An overview and integration. In D. C. Molden (Ed.), Understanding priming effects in social psychology (pp. 252-258). Guilford Press.

Pessiglione, M., Schmidt, L., Draganski, B., Kalisch, R., Lau, H., Dolan, R. J., \& Frith, C. D. (2007). How the brain translates money into force: A neuroimaging study of subliminal motivation. Science, 316(5826), 904-906. https://doi.org/10.1126/science.1140459

Seijts, G. H., \& Latham, G. P. (2005). Learning versus performance goals: When should each be used? Academy of Mangement Perspectives, 19, 124-131.

Seijts, G. H., \& Latham, G. P. (2011). The effect of commitment to a learning goal, self-efficacy, and the interaction between learning goal difficulty and commitment on performance in a business simulation. Human Performance, 24, 189-204.

Shanks, D. R., Newell, B. R., Lee, E. H., Balakrishnan, D., Ekelund, L., Cenac, Z., ... Moore, C. (2013). Priming intelligent behavior: An elusive phenomenon. PloS one, 8, e56515.

Shantz, A., \& Latham, G. P. (2009). An exploratory field experiment of the effect of subconscious and conscious goals on employee performance. Organizational Behavior and Human Decision Processes, 109, 9-17. https://doi.org/10.1016/j.obhdp.2009.01.001

Shantz, A., \& Latham, G. P. (2011). The effect of primed goals on employee performance: Implications for human resource management. Human Resource Management, 50, 289-299.

Stajkovic, A. D., Locke, E. A., \& Blair, E. S. (2006). A first examination of the relationships between primed subconscious goals, assigned conscious goals, and task performance. Journal of Applied Psychology, 91(5), 1172-1180.

Stajkovic, A., Latham, G. P., Sergent, K., \& Petersen, S. (2018). Prime and performance: Can a CEO motivate employees without their awareness? Journal of Business and Psychology, 34(5), 791-802. https://doi.org/10.1007/s10869-018-9598-x

Takarada, Y., \& Nozaki, D. (2018). Motivational goal-priming with or without awareness produces faster and stronger force exertion. Scientific Reports, 8(1), no. 10135.

Weingarten, E., Chen, Q., McAdams, M., Yi, J., Hepler, J., \& Albarracín, D. (2016). From primed concepts to action: A meta-analysis of the behavioral effects of incidentally presented words. Psychological Bulletin, 142(5), 472-497. https://doi.org/10.1037/bul0000030

Winters, D., \& Latham, G. P. (1996). The effect of learning versus outcome goals on a simple versus a complex task. Group and Organization Management, 21, 236-250. 